\title{
Perivascular PDGFR- $\beta$ is an independent marker for prognosis in renal cell carcinoma
}

\author{
Magnus Frödin ${ }^{*}$, Artur Mezheyeuski ${ }^{1}$, Sara Corvigno ${ }^{1}$, Ulrika Harmenberg ${ }^{1,2}$, Per Sandström ${ }^{1}$, \\ Lars Egevad ${ }^{1,3,5}$, Martin Johansson ${ }^{4,5}$ and Arne Östman ${ }^{1}$ \\ ${ }^{1}$ Department of Pathology-Oncology, Karolinska Institutet, Stockholm, Sweden; ${ }^{2}$ Department of Clinical Oncology, Karolinska \\ University Hospital, Stockholm, Sweden; ${ }^{3}$ Department of Clinical Pathology, Karolinska University Hospital, Stockholm, Sweden \\ and ${ }^{4}$ Department of Translational Medicine, Clinical Pathology, Lund University, Lund, Sweden
}

\begin{abstract}
Background: Renal cell carcinoma (RCC) is a highly vascularised tumour, where anti-angiogenic treatment with multi-tyrosinekinase-inhibitor, is used for first-line treatment of metastatic disease. Variations in vascular characteristics are likely to contribute to variations in intrinsic aggressiveness of the disease. Emerging studies are identifying perivascular status, including perivascular PDGFR- $\beta$, as a determinant of prognosis in other tumour types.
\end{abstract}

Methods: This work explored the impact on prognosis of vascular characteristics in RCC through analyses of a population-based collection of tumours from surgery-alone-treated patients. The quantitative data from a panel of vascular metrics were obtained through computerised image analysis of sections double-stained for expression of the endothelial cell marker CD34 together with perivascular markers $\alpha$-SMA or PDGFR- $\beta$.

Results: Perivascular expression of PDGFR- $\beta$ and $\alpha$-SMA were positively correlated to each other, and negatively correlated to vessel density. High expression of PDGFR- $\beta$ and $\alpha$-SMA as well as low vessel density was significantly associated with short survival in uniand multivariate analyses. Subgroup analyses demonstrated that the prognostic impact of the perivascular markers was particularly prominent in the T4-subgroup. A novel metric, related to PDGFR- $\beta$ perivascular heterogeneity, was also associated with prognosis in uni-and multi-variate analyses. This novel metric also acted as a prognosis marker in ovarian cancer.

Conclusions: The study demonstrates previously unrecognised associations between RCC survival and the absolute levels, and variability, of perivascular PDGFR- $\beta$. This marker should be further explored in other RCC cohorts. Findings also suggest mechanistic analyses and studies on the relationship between perivascular status and efficacy of multi-tyrosine-kinase-inhibitors.

Anti-angiogenic drugs are used as first-line treatment in metastatic renal cell cancer (mRCC) (Shen and Kaelin, 2013). Many patients display intrinsic resistance to these agents and others will develop resistance after some time of treatment. Primary resistance to targeted therapy in other cancers are often linked to mutational events in genes coding for the target receptor (Bertotti et al, 2015). However, in mRCC, the primary resistance to VEGF-targeted therapy is generally not based on mutations of the VEGF receptor. It is therefore likely that RCC display clinically relevant variations in angiogenic features that impact both on natural course and sensitivity to anti-angiogenic drugs.
These findings suggest clinically relevant variations in angiogenic features, including pericyte status, of RCC.

Pericytes are candidate regulators of tumour biology (Armulik et al, 2011). Context-dependent pro- or anti-tumoural effects have been demonstrated in different experimental tumour models (Furuhashi et al, 2004; McCarty et al, 2007). Furthermore, depletion of pericytes in experimental primary tumours has been shown to enhance metastatis through mechanisms possibly involving tumour hypoxia and enhanced cancer cell intravasation (Xian et al, 2006; Cooke et al, 2012; Keskin et al, 2015). Other studies have instead noted prometastatic effects of PDGFR- $\beta$ -

*Correspondence: Dr M Frödin-Bolling; E-mail: magnus.frodin@ki.se

${ }^{5}$ These authors contributed equally to this work.

Received 7 July 2016; revised 17 October 2016; accepted 10 November 2016; published online 8 December 2016

(c) 2017 Cancer Research UK. All rights reserved 0007-0920/17 
positive pericytes (Yang et al, 2016). Finally, reduced perivascular coverage has been shown to facilitate infiltration of tumours by immune-suppressive myeloid-derived suppressor cells, ultimately leading to reduced immune-surveillance and increased tumour growth (Hong et al, 2015).

A number of studies have analysed the relationships between outcome and tumour vascularity in renal carcinoma with partially conflicting results. In a meta-analysis containing 14 studies, four studies involving 289 patients showed a correlation between high microvessel density and poor outcome. The remaining 10 studies, involving 826 patients, did not show any correlation with microvessel density and prognosis (Cheng et al, 2014). Thus, the grade of maturation of vessels might be important, as well as the extent of pericyte coverage. This notion has been supported by studies demonstrating that a higher pericyte coverage was related with more aggressive disease and that the MVD:PC ratio was a more reliable prognostic factor than MVD alone (Yao et al, 2007; Cao et al, 2013).

Associations between perivascular markers, including PDGFR- $\beta$ and survival have been reported in other tumour types. A recent study found that high expression of PDGFR- $\beta$ in perivascular cells in serous ovarian carcinoma was significantly correlated to worse outcome (Corvigno et al, 2016). In contrast, increased perivascular PDGFR- $\beta$ in primary colorectal cancer was associated with shorter survival in subsequent metastatic disease (Mezheyeuski et al, 2016). The latter findings might eventually reflect effects of perivascular status on response to treatment.

The aim of the present study was to further explore the relationships between vascular features and outcome in RCC through a digital-image-analyses-supported approach for quantitative characterisation of tumour vasculature, including perivascular properties.

\section{MATERIALS AND METHODS}

Patient and tumour material. Three-hundred and fourteen patients affected by renal cell cancer, diagnosed between 1978 and 1996 at Skåne University Hospital Malmö, were included in the study. The data of the patient cohort including sex, age, tumour stage, Fuhrman grade, metastasis present at diagnosis, pathologic classification and survival time were retrieved from clinical registries (Table 1). None of the patients had received adjuvant therapy. Sections from primary tumours were revised by a certified pathologist; diagnosis of renal cell carcinoma was confirmed and representative tumour areas were chosen, and formalin-fixed paraffin-embedded (FFPE) blocks were retrieved and used to construct a TMA containing two punches per tumour block with a diameter of $1 \mathrm{~mm}$.

The ovarian cancer cohort, including cases receiving or not receiving chemotherapy, is described in detail elsewhere (Corvigno et al, 2016).

IHC procedures. TMA sections were deparaffinised, rehydrated and washed in distilled $\mathrm{H}_{2} \mathrm{O}$. After antigen retrieval in decloaking chamber (Biocare Medical) at $110{ }^{\circ} \mathrm{C}$ for $5 \mathrm{~min}$ in $\mathrm{pH} 10.0$ retrieval buffer, (for PDGFR- $\beta$ ) or $\mathrm{pH} 9.0$ (for $\alpha$-SMA), sections were incubated with blocking solution for $30 \mathrm{~min}$ and then incubated

Table 1. Perivascular and vessel metrics acted as prognostic factors for overall survival in multivariate analysis correcting for age, sex, tumour stage, nuclear grade and histopathological classification

\begin{tabular}{|c|c|c|c|c|c|c|c|c|c|c|c|c|c|}
\hline \multirow[b]{2}{*}{ Variable } & \multirow[b]{2}{*}{$\mathrm{nr}$} & \multicolumn{3}{|c|}{ PDGFR- $\beta$} & \multicolumn{3}{|c|}{$\alpha-S M A$} & \multicolumn{3}{|c|}{ VD } & \multicolumn{3}{|c|}{ PDGFR- $\beta$ PVI IQR } \\
\hline & & HR & $95 \% \mathrm{Cl}$ & $P$-value & HR & $95 \% \mathrm{Cl}$ & $P$-value & HR & $95 \% \mathrm{Cl}$ & $P$-value & $\mathrm{HR}$ & $95 \% \mathrm{Cl}$ & $P$-value \\
\hline \multicolumn{14}{|l|}{ Age (37-89) } \\
\hline $\begin{array}{l}<50 \\
>50\end{array}$ & $\begin{array}{r}31 \\
283\end{array}$ & \begin{tabular}{l|} 
ref. \\
0.400
\end{tabular} & $0.133-1.204$ & 0.103 & \begin{tabular}{l|} 
ref. \\
0.415
\end{tabular} & $0.121-1.420$ & 0.161 & \begin{tabular}{l|} 
ref. \\
0.429
\end{tabular} & $0.143-1.287$ & 0.131 & \begin{tabular}{l|} 
ref. \\
0.396
\end{tabular} & $0.131-1.195$ & 0.100 \\
\hline \multicolumn{14}{|l|}{ Sex } \\
\hline $\begin{array}{l}\text { Male } \\
\text { Female }\end{array}$ & $\begin{array}{l}179 \\
135\end{array}$ & \begin{tabular}{l|} 
ref. \\
1.171
\end{tabular} & $0.633-2.166$ & 0.615 & 1.505 & $0.779-2.908$ & 0.224 & \begin{tabular}{l|} 
ref. \\
1.054
\end{tabular} & $0.561-1.979$ & 0.870 & \begin{tabular}{l|} 
ref. \\
1.210
\end{tabular} & $0.651-2.247$ & 0.547 \\
\hline \multicolumn{14}{|l|}{ T-stage } \\
\hline $\begin{array}{l}\text { T-1 } \\
\text { T-2 } \\
\text { T-3 } \\
\text { T-4 } \\
\text { Unclassified }\end{array}$ & $\begin{array}{r}35 \\
40 \\
35 \\
66 \\
139\end{array}$ & \begin{tabular}{c|} 
ref. \\
2.496 \\
5.870 \\
12.781
\end{tabular} & $\begin{array}{l}0.494-12.603 \\
1.243-27.711 \\
2.844-57.443\end{array}$ & $\begin{array}{l}0.268 \\
0.025 \\
0.001\end{array}$ & \begin{tabular}{c|} 
ref. \\
2.231 \\
4.022 \\
17.602
\end{tabular} & $\begin{array}{l}0.429-11.606 \\
0.761-21.243 \\
3.711-83.493\end{array}$ & $\begin{array}{l}0.340 \\
0.101 \\
0.000\end{array}$ & \begin{tabular}{|c|} 
ref. \\
2.290 \\
5.179 \\
12.581
\end{tabular} & $\begin{array}{l}0.450-11.670 \\
1.097-24.457 \\
2.776-57.024\end{array}$ & $\begin{array}{l}0.319 \\
0.038 \\
0.001\end{array}$ & \begin{tabular}{c|} 
ref. \\
2.424 \\
5.554 \\
12.256
\end{tabular} & $\begin{array}{l}0.479-12263 \\
1.174-26.265 \\
2.727-55.091\end{array}$ & $\begin{array}{l}0.284 \\
0.031 \\
0.001\end{array}$ \\
\hline \multicolumn{14}{|l|}{ Grade } \\
\hline $\begin{array}{l}\text { Fuhrman I } \\
\text { Fuhrman II } \\
\text { Fuhrman III } \\
\text { Fuhrman IV } \\
\text { Unclassified }\end{array}$ & $\begin{array}{r}121 \\
110 \\
56 \\
22 \\
5\end{array}$ & \begin{tabular}{l|} 
ref. \\
1.150 \\
1.658 \\
1.740
\end{tabular} & $\begin{array}{l}0.503-2.630 \\
0.694-3.960 \\
0.519-5.827\end{array}$ & $\begin{array}{l}0.740 \\
0.255 \\
0.369\end{array}$ & \begin{tabular}{l|} 
ref. \\
0.905 \\
0.766 \\
1.241
\end{tabular} & $\begin{array}{l}0.321-2.554 \\
0.277-2.117 \\
0.274-5.632\end{array}$ & $\begin{array}{l}0.851 \\
0.607 \\
0.779\end{array}$ & \begin{tabular}{l|} 
ref. \\
1.076 \\
1.656 \\
1.877
\end{tabular} & $\begin{array}{l}0.454-2.551 \\
0.675-4.064 \\
0.560-6.295\end{array}$ & $\begin{array}{l}0.868 \\
0.271 \\
0.308\end{array}$ & \begin{tabular}{l|} 
ref. \\
1.170 \\
1.745 \\
1.831
\end{tabular} & $\begin{array}{l}0.513-2.669 \\
0.734-4.151 \\
0.550-6.094\end{array}$ & $\begin{array}{l}0.709 \\
0.208 \\
0.324\end{array}$ \\
\hline \multicolumn{14}{|c|}{ Metastasis at diagnosis } \\
\hline $\begin{array}{l}\text { M0 } \\
\text { M1 }\end{array}$ & $\begin{array}{r}254 \\
60 \\
\end{array}$ & \begin{tabular}{c|} 
ref. \\
3.379
\end{tabular} & $1.479-7.722$ & 0.004 & \begin{tabular}{l|} 
ref. \\
3.871
\end{tabular} & $1.556-9.636$ & 0.004 & \begin{tabular}{l|} 
ref. \\
3.202
\end{tabular} & $1.413-7.258$ & 0.005 & \begin{tabular}{l|} 
ref. \\
3.418
\end{tabular} & $1.486-7.864$ & 0.004 \\
\hline \multicolumn{14}{|l|}{ Histology } \\
\hline $\begin{array}{l}\text { Non-clear cell } \\
\text { Clear cell } \\
\text { Unclassified }\end{array}$ & $\begin{array}{r}22 \\
248 \\
42\end{array}$ & \begin{tabular}{l|} 
ref. \\
1.483
\end{tabular} & $0.487-4.519$ & 0.488 & $\begin{array}{l}\text { ref. } \\
2.446\end{array}$ & $0.549-10.900$ & 0.241 & \begin{tabular}{l|} 
ref. \\
1.183
\end{tabular} & $0.379-3.689$ & 0.772 & \begin{tabular}{l|} 
ref. \\
1.406
\end{tabular} & $0.464-4.263$ & 0.547 \\
\hline PDGFR- $\beta$ FCV & & 2.322 & $1.233-4.372$ & 0.009 & & & & & & & & & \\
\hline$\alpha$-SMA FCV & & & & & 2.466 & $1.108-5.488$ & 0.027 & & & & & & \\
\hline VD & & & & & & & & 1.961 & $1.038-3.704$ & 0.038 & & & \\
\hline PDGFR- $\beta$ PVI IQR & & & & & & & & & & & 2.244 & $1.186-4.246$ & 0.013 \\
\hline
\end{tabular}


overnight with antibodies against PDGFR- $\beta$ (No. 3169 Cell Signaling Technology, Danvers, MA, USA at dilution $1: 100$ ) or $\alpha$-SMA (Clone 1A4; Dako, Inc., Denmark at dilution $1: 300$ ). Sections were then incubated with polymer system (ImmPRESSAP Polymer Anti-Rabbit IgG MP-5401 or ImmPRESS-AP Polymer Anti-Mouse IgG, MP-5402, Vector Laboratories, Burlingame, CA, USA) for $1 \mathrm{~h}$ at room temperature and developed with Vector Blue AP Substrate Kit (SK-5300, Vector Laboratories).

To destroy alkaline phosphatases activity, sections were subsequently heated in decloaking chamber at $95^{\circ} \mathrm{C}$ for $5 \mathrm{~min}$, in $\mathrm{pH} 9.0$ buffer, and then incubated with blocking solution for 30 min. Primary antibody against CD34 (Clone JC70A) at a $1: 100$ dilution was added for overnight incubation at $4{ }^{\circ} \mathrm{C}$. Sections were then incubated with polymer system (ImmPRESS-AP Polymer Anti-Mouse IgG, MP-5402, Vector Laboratories) for $1 \mathrm{~h}$ at room temperature and developed with Vector Red AP Substrate Kit (SK5100, Vector Laboratories).

Digital image analyses. Details concerning digital image analyses have been previously reported (Corvigno et al, 2016; Mezheyeuski et al, 2016). In short, the double-stained slides were scanned by a VSlide slide scanning microscope (Metasystems, Alltlussheim, Germany) using $\times 10$ objective and RGB LED illumination for colour deconvolution. To view the scanned digital slides analyses, the program Metaviewer (Metasystems) was used. Regions of interest (ROI) were then manually annotated and processed with an in-housebuilt image analysis algorithm based on the Image J-software (NIH, Bethesda, MD, USA). The computerised algorithm utilises specific endothelial staining (in this case CD34) to identify vessels. Perivascular areas are then defined as the area within $5.5 \mu \mathrm{m}$ of the stained vessel. After this selection, the intensity of the specific marker is calculated for each perivascular region. Each case is therefore linked to a list of vessels with the perivascular intensity determined for each vessel.

A series of perivascular and vascular stroma metrics were produced as continuous variables:

Vessel density (VD) was calculated as a ratio of the number of vessels/tumour area. Vessel diameter was defined for each vessel, calculated as minimal dimension of the vessel profile in the image. Median value of vessel diameters on the TMA core was used to characterise each patient/case.

Perivascular intensity (PVI) was defined as optical density (OD) of the perivascular staining. The fraction of covered vessels (FCV) was obtained by classifying individual vessels as 'uncovered' (OD value $\leqslant 0.5$ of maximal detected $\mathrm{OD}$ ) or 'covered' (OD value $>0.5$ of maximal detected OD). The ratio of covered vessels over total vessels per case was then calculated to produce the metric FCV. For an in-depth description, we refer to Supplementary item 3, picture A-C in (Mezheyeuski et al, 2016).

To measure the heterogeneity of PDGFR- $\beta$ within each tumour, the inter-quartile range of all vessels in each tumour was calculated.

The two cores of each case in general showed good concordance. Concerning PDGFR- $\beta$, in the FCV group with total score high, 22 of 136 were disconcordant and in the group with total score low, there were 29 out of 151 . For $\alpha$-SMA total score high, 18 was disconcordant and in the group with total score low, 15 was disconcordant (Supplementary Table 1).

Statistical analysis. For correlation between continuous variables, Spearmańs two-tailed test was used. For means comparisons of variables inside the different clinico-pathological subgroups, Mann-Withney and Kruskal-Wallis tests were performed. For survival analyses, variables were dichotomised according to median and Kaplan-Meier curves with log-rank test were produced. Cox regression analysis was performed both with uni- and multivariate settings using dichotomised variables. The $P$-value cutoff for statistical significance was set as 0.05 .
For illustration of marker impact on survival in different patient subgroups, Forest-plots were generated in Microsoft Office Excel 2010 (Microsoft Inc., Redmond, WA, USA). For other statistical analysis, the SPSS V20-software (SPSS Inc., Chicago, IL, USA) and R 3.2.2. Meta package were used.

\section{RESULTS}

PDGFR- $\beta$ and $\alpha$-SMA show independent and heterogeneous perivascular expression in RCC. A set of double IHC stainings were performed where either PDGFR- $\beta$ or $\alpha$-SMA antibodies were used together with antibodies against the endothelial cell marker CD34. Digital images of stainings were subsequently analysed to extract the quantitative data on vessel density, vessel size and perivascular status (see Material and Methods and (Corvigno et al, 2016; Mezheyeuski et al, 2016) for details). For each of the two perivascular markers, two metrics were collected: fraction of covered vessels (FCV) and median intensity of staining in perivascular areas (PVI).

Initial analysis demonstrated large inter-case heterogeneity between the tumours where all four possible combinations of perivascular marker status occurred (double high, double low, PDGFR- $\beta$ single high, $\alpha$-SMA single high) (Figure 1).

The next analysis focused on correlations between the different metrics. Both perivascular markers considered as fraction of covered vessels (FCV) were negatively correlated to vessel density, but neither was correlated to vessel size (Figure 2). Positive correlation was also detected between expression of the two perivascular markers (Figure 2).

Vascular and perivascular metrics are significantly associated with clinicopathological characteristics. The quantitative data from the vascular and perivascular profiling was also used to investigate potential associations between these features and standard clinico-pathological characteristics.

High perivascular PDGFR- $\beta$ expression was associated with high tumour stage and high Fuhrman grade $(P<0.001$ and $P=0.043$, respectively, Supplementary Table 2.) High perivascular $\alpha$-SMA was significantly associated with high Fuhrman grade $(P<0.001)$, but not to stage.

The data on vessel size and vessel diameter were also analysed with regard to associations with clinico-pathological characteristics. For both metrics, there was an association with high Fuhrman grade $(P<0.001)$. Low vessel size but not vessel density was associated with high T-stage. Interestingly, an association was seen between male sex and low vessel density $(P=0.002)$.

High perivascular PDGFR- $\beta$ and $\alpha$-SMA are independent markers for poor prognosis in RCC. Perivascular PDGFR- $\beta$ and $\alpha$-SMA status were then analysed with regard to their associations with survival.

The analyses revealed a statistically significant relationship between high FCV of PDGFR- $\beta$ and $\alpha$-SMA, and shorter overall survival (OS). For low PDGFR- $\beta$, median survival was 48 months vs 26 months for high PDGFR- $\beta(P<0.001$ at log-rank test, $P<0.001$. Univariat Cox regression: HR 1.9, 95\% CI: 1.4-2.6) (Figure 3). For $\alpha$-SMA, median OS in the low-expression group was 52 months vs 29 months in the high-expression group $(P<0.026$ at log-rank test. Univariate Cox regression: $P<0.028$, HR 1.4(95\% CI: 1.0-2.0) (Figure 3). Low vessel density was associated with worse outcome (median survival 29 months vs 43 months, $P<0.001$ at log-rank test. $P<0.001 \mathrm{HR} 1.8,95 \% \mathrm{CI}$ : $1.3-2.5$ at univariate analysis) (Figure 3 ).

These univariate analyses were expanded to a multivariate analysis, including $\mathrm{T}$-stage, nuclear grade, histology, metastatic disease upon presentation, patient age and sex. In this analysis, perivascular metrics for $\alpha$-SMA and PDGFR- $\beta$ as well as 


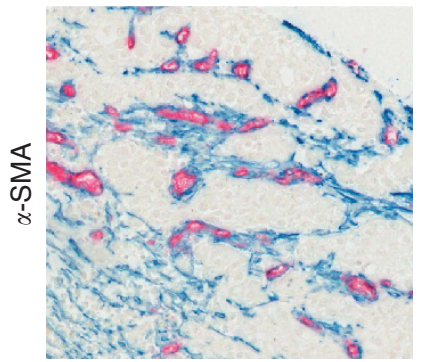

High

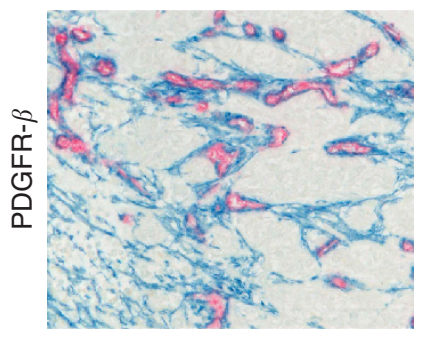

High

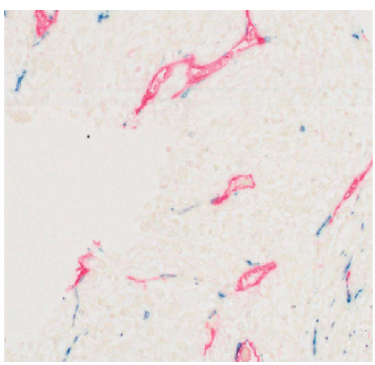

Low

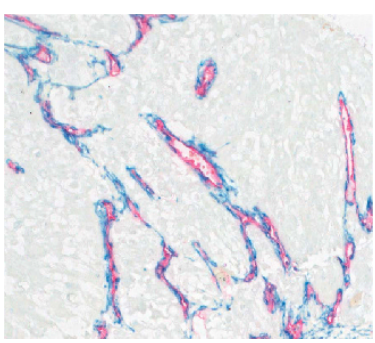

High

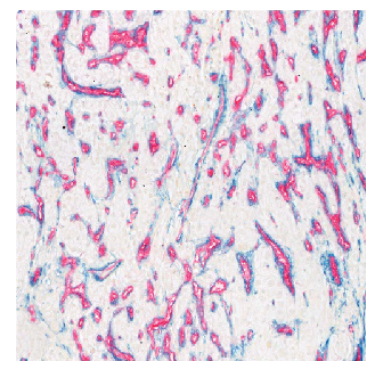

High

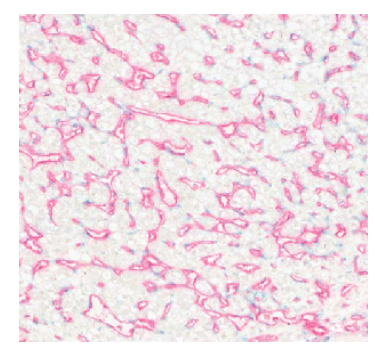

Low

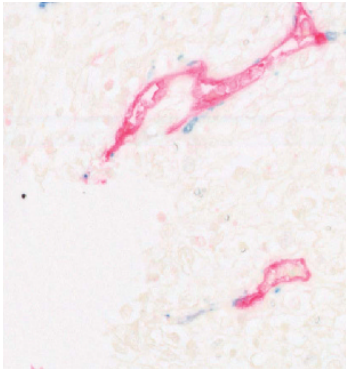

Low

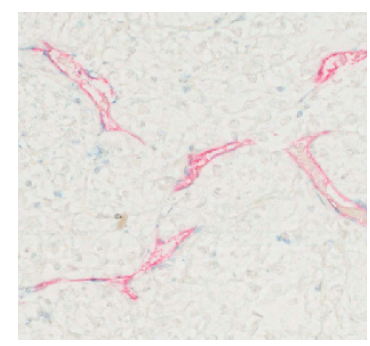

Low

Figure 1. PDGFR- $\beta$ and $\alpha$-SMA show variable and independent perivascular expression in RCC. Microphotographs showing examples of tumours with different expression profiles of PDGFR- $\beta$ (blue; upper part) and $\alpha$-SMA (blue; lower part) in sections also stained with CD34 (red). The four cases show high expression of both markers (left), low expression of both markers (right) or high expression of only PDGFR- $\beta$ (middle left) or only $\alpha$ SMA (middle right).
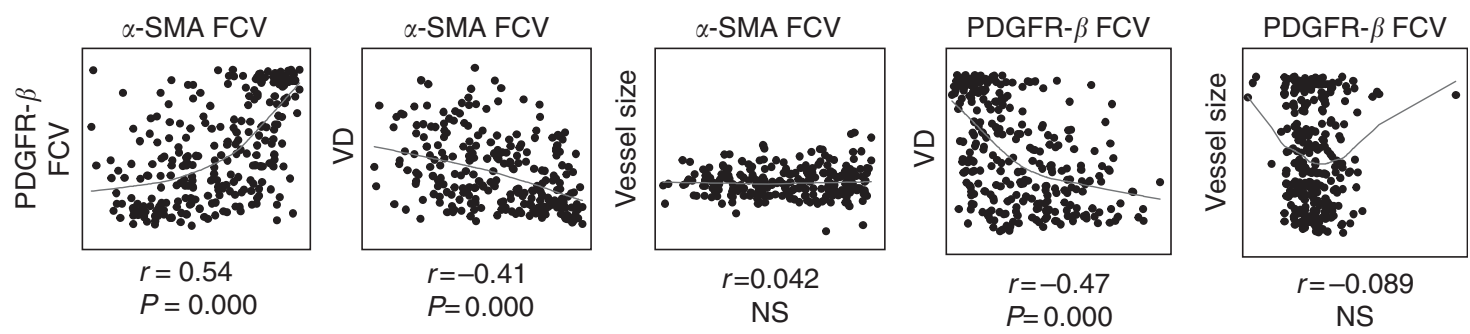

Figure 2. Associations between vessel size, vessel density, perivascular $\alpha$-SMA and perivascular PDGFR- $\beta$ in RCC. Scatter-plots, including Spearman correlation coefficients and $P$-values, illustrating correlations between different vascular metrics.
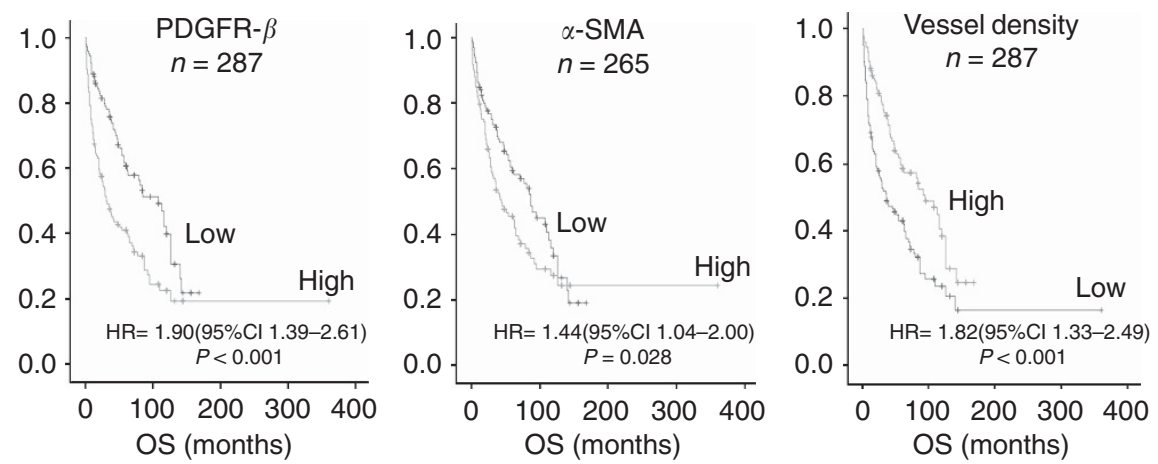

Figure 3. Associations of PDGFR- $\beta$ FCV, $\alpha$-SMA FCV and vessel density with overall survival (OS) in RCC. Kaplan-Meier curves for overall survival (OS) in RCC cases defined by perivascular PDGFR- $\beta$ FCV (left), perivascular $\alpha$-SMA FCV (middle) and vessel density (right).

vessel density acted as independent predictors for overall survival (Table 1).

Perivascular markers show particularly strong prognostic impact in stage T4 RCC. A set of exploratory analyses was performed to investigate the impact on survival of the perivascular markers in subgroups of patients stratified according to their clinico-pathological features.

The forest plots in Figure 4 shows statistically significant association of high PDGFR- $\beta$ FCV with poor survival in patients with high T- stage of disease (T4), older patients, male patients and patients with clear cell type renal cancer (Figure 4). High $\alpha$-SMA FCV was correlated to poor survival in T4-tumours and tumours 
of clear cell type. Also, VD showed a strong association with survival in the T4 group. This was also seen in the subgroups with higher age, clear cell histology, metastasis at diagnosis and in female patients.

On the basis of these findings, multivariate analyses were performed for the T4-stage group. This showed that both perivascular markers but not VD acted as independent markers for prognosis in this subgroup (Table 2).

Heterogeneity of perivascular PDGFR- $\beta$ predicts prognosis. The availability of the data regarding perivascular status of individual vessels allowed determination of an index related to intra-case heterogeneity of perivascular intensity, designated PVI (IQR).
Analyses of PDGFR- $\beta$ PVI (IQR) showed that high heterogeneity was significantly associated with shorter survival in univariate analysis (Cox regression: HR 1.95, 95\% CI 1.43-2.68, $P<0.001$ ) (Figure 5A), and in multivariate analysis (Cox regression: HR 2.08, 95\% CI: $1.12-3.83 \quad P<0.02)$ correcting for clinicopathological characteristics (Table 1).

This novel metric was also tested in an ovarian cohort, which has previously been characterised with regard to perivascular metrics (Corvigno et al, 2016). Also, in this cohort, high PDGFR- $\beta$ PVI (IQR) was associated with shorter survival in uni- and multivariate analyses (univariate, Cox regression: $\mathrm{HR} 1.99,95 \% \mathrm{CI}$ : 1.25-3.16, $P=0.004$; multivariate, Cox regression: HR 1.53, 95\% CI: 0.95-2.47 $P=0.08$, (Figure 5B; Supplementary Table 3).

Subgroup analyses of the RCC cohort indicated prominent impact of PDGFR- $\beta$ PVI (IQR) in the T4 group (Figure 5C),
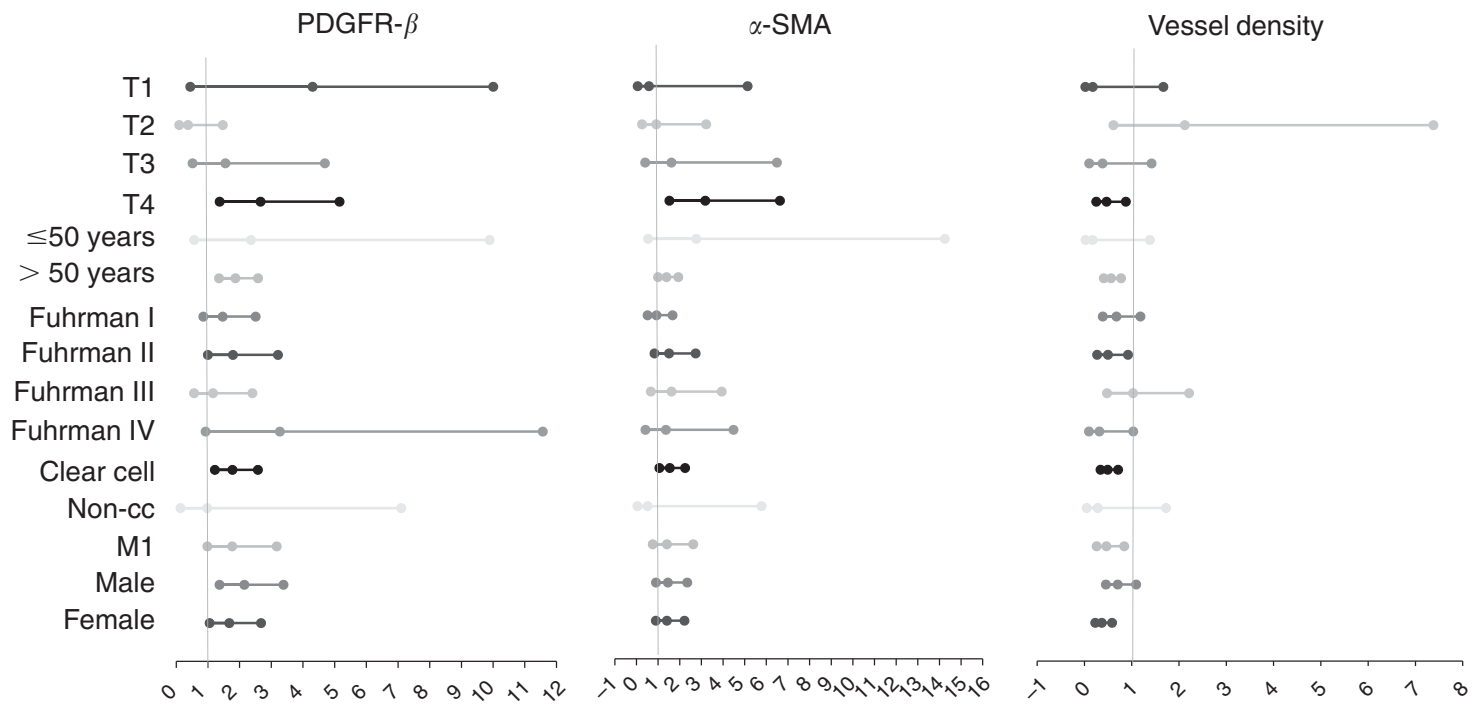

Figure 4. Associations of PDGFR- $\beta$ FCV, $\alpha$-SMA FCV and vessel density with overall survival (OS) in subgroups of RCC. Forest-plots showing the $H R$, including confidence intervals of the various metrics in clinical subgroups of RCC.

Table 2. Multivariate analysis in the subgroup of T4-tumours shows that both PDGFR- $\beta$ and $\alpha$-SMA as well as the heterogeneity of PDGFR- $\beta$ remain significant when correcting for age, sex, nuclear grade and histopathological classification

\begin{tabular}{|c|c|c|c|c|c|c|c|c|c|c|}
\hline Variable & $\mathrm{nr}$ & HR & $95 \% \mathrm{Cl}$ & $P$-value & HR & $95 \% \mathrm{Cl}$ & $P$-value & HR & $95 \% \mathrm{Cl}$ & $P$-value \\
\hline \multicolumn{11}{|l|}{ Age (37-89) } \\
\hline $\begin{array}{l}<50 \\
>50\end{array}$ & $\begin{array}{r}6 \\
60\end{array}$ & $\begin{array}{c}\text { ref. } \\
0.641\end{array}$ & $0.206-1.991$ & 0.442 & $\begin{array}{c}\text { ref. } \\
0.923\end{array}$ & $0.243-3.505$ & 0.906 & $\begin{array}{l}\text { ref. } \\
1.550\end{array}$ & $0.497-4.835$ & 0.450 \\
\hline \multicolumn{11}{|l|}{ Sex } \\
\hline $\begin{array}{l}\text { Female } \\
\text { Male }\end{array}$ & $\begin{array}{l}40 \\
26\end{array}$ & $\begin{array}{l}\text { ref. } \\
1.521\end{array}$ & $0.709-3.265$ & 0.282 & $\begin{array}{l}\text { ref. } \\
1.431\end{array}$ & $0.639-3.203$ & 0.38 & 1.512 & $0.675-3.387$ & 0.315 \\
\hline \multicolumn{11}{|l|}{ Grade } \\
\hline $\begin{array}{l}\text { Fuhrman I } \\
\text { Fuhrman II } \\
\text { Fuhrman III } \\
\text { Fuhrman IV } \\
\text { Unclassified }\end{array}$ & $\begin{array}{r}8 \\
12 \\
16 \\
6 \\
24\end{array}$ & $\begin{array}{c}\text { ref. } \\
1.627 \\
2.221 \\
3.582\end{array}$ & $\begin{array}{c}0.480-5.513 \\
0.712-6.929 \\
0.918-13.980\end{array}$ & $\begin{array}{l}0.434 \\
0.169 \\
0.066\end{array}$ & $\begin{array}{c}\text { ref. } \\
3.208 \\
2.293 \\
7.399\end{array}$ & $\begin{array}{c}0.713-14.435 \\
0.638-8.238 \\
1.318-41.548\end{array}$ & $\begin{array}{l}0.129 \\
0.204 \\
0.023\end{array}$ & $\begin{array}{c}\text { ref. } \\
1.976 \\
2.703 \\
4.365\end{array}$ & $\begin{array}{c}0.578-6.748 \\
0.856-8.535 \\
1.118-17.051\end{array}$ & $\begin{array}{l}0.277 \\
0.090 \\
0.034\end{array}$ \\
\hline \multicolumn{11}{|l|}{ Histology } \\
\hline $\begin{array}{l}\text { Non-clear cell } \\
\text { Clear cell } \\
\text { Unclassified }\end{array}$ & $\begin{array}{r}3 \\
39 \\
24\end{array}$ & $\begin{array}{r}\text { ref. } \\
3.07\end{array}$ & $0.669-14.096$ & 0.149 & $\begin{array}{c}\text { ref. } \\
4.237\end{array}$ & $0.513-34.955$ & 0.18 & $\begin{array}{l}\text { ref. } \\
3.941\end{array}$ & $0.478-32.523$ & 0.203 \\
\hline PDGFR- $\beta$ FCV & & 3.107 & $1.345-7.177$ & 0.008 & & & & & & \\
\hline$\alpha-S M A$ FCV & & & & & 3.283 & $1.059-10.176$ & 0.039 & & & \\
\hline PDGFR- $\beta$ PVI IQR & & & & & & & & 2.826 & $1.209-6.605$ & 0.016 \\
\hline
\end{tabular}


A

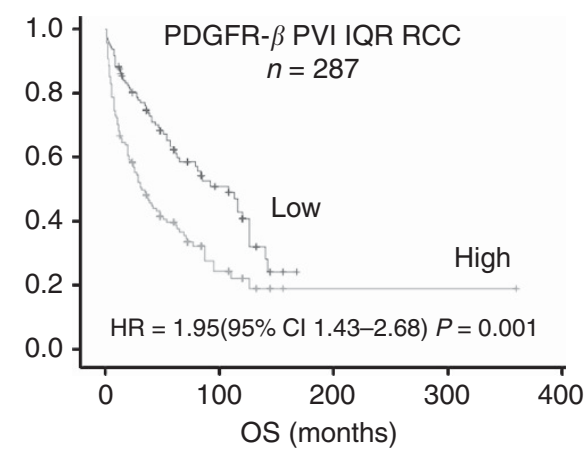

B

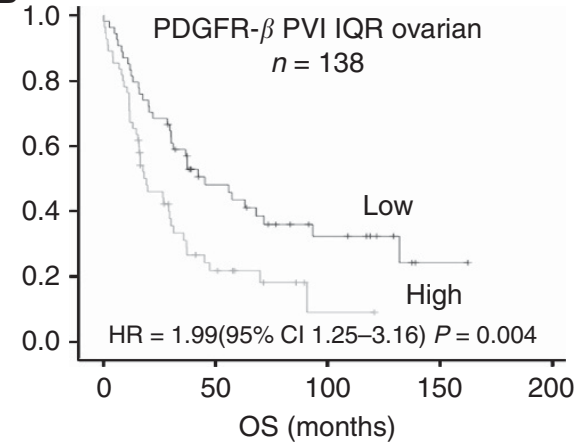

C

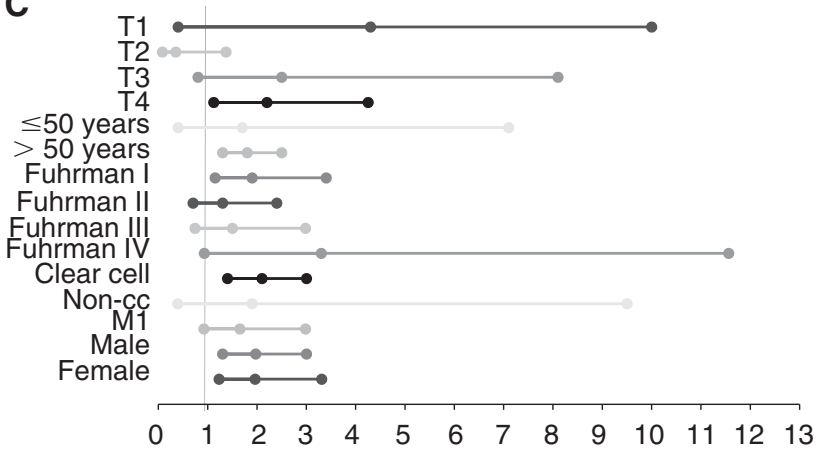

Figure 5. Associations of PDGFR- $\beta$ PVI (IQR) with overall survival (OS) in RCC and serous ovarian cancer. Kaplan-Meier curves for overall survival (OS) in RCC cases (A) and serous ovarian cancer (B) defined by PDGFR- $\beta$ PVI (IQR), and forest-plots showing the HRs, including confidence intervals, of PDGFR- $\beta$ PVI (IQR) in clinical subgroups of RCC (C). A full colour version of this figure is available at British Journal of Cancer online.

where this metric was significantly associated with survival (univariate Cox-regression $P<0.022$, HR 2.2, 95\% CI: 1.1-4.2). This association remained significant in a multivariate analysis (Table 2).

\section{DISCUSSION}

A major novel finding of the present study is the identification of high perivascular PDGFR- $\beta$ expression as an independent marker for poor prognosis in RCC. This finding is in agreement with the recently published data from serous ovarian cancer where perivascular PDGFR- $\beta$ was also associated with shorter survival (Corvigno et al, 2016). Experimental studies have detected pro- as well as anti-metastatic effects of the perivascular cells (Xian et al, 2006; Cooke et al, 2012; Keskin et al, 2015; Yang et al, 2016). Concerning the pro-metastatic effects, mechanisms were proposed, including IL-33-dependent recruitment by perivascular cells of pro-metastatic TAMs (Yang et al, 2016). The model studies thereby suggest further correlative analyses in clinical samples exploring potential positive associations between perivascular and macrophage status. Future studies should also address the relationships between perivascular status and the recently identified poor-prognosis RCC endothelial markers MCAM and LAMA4 (Wragg et al, 2016). Future studies can also consider an improved spatial resolution of the analyses allowing a better distinction between perivascular cells that are true pericytes, as defined by embedment in the basement membrane, and more loosely attached cells.

The analyses of associations with clinic-pathological characteristics revealed an association between stage and perivascular status (Supplementary Table 1). This finding is in agreement with an earlier study, which also reported an association between perivascular PDGF-B/PDGFR- $\beta$ expression and stage (Song et al, 2014).

A noteworthy finding from the exploratory subgroup analyses was the indication that the prognostic impact of perivascular PDGFR- $\beta$ was particularly prominent in the T4 subgroup. The present study does not further investigate the mechanistic basis for this finding. However, the observation imply that vascular maturation is a more critical rate-limiting step in the group of T4 tumours, which invade surrounding organs, than for the T1-T3 tumours, which do not extend beyond Gerotas fascia where other features have greater impact on aggressiveness.

The multi-metric analyses of tumour vasculature of the present study also allowed correlation analyses, suggesting mechanisms involved in RCC angiogenesis. These include the detection of significant associations between perivascular status and vessel size, but not vessel density. The former is compatible with earlier vascular biology studies implying perivascular cells in vessel maturation and function (Armulik et al, 2011). The absence of relationship between vessel density and perivascular status indicate that these features are controlled by distinct and independent mechanisms. Candidate growth factors controlling these separate aspects include VEGF-A for vessel density and PDGF-BB for perivascular status and vessel maturation.

A novelty of the present study is the demonstration that perivascular heterogeneity in RCC acts as an independent marker for prognosis. It is becoming increasingly recognised that inter-case heterogeneity regarding cancer cell mutation status, or multi-clonality, is associated with poor prognosis (Landau et al, 2013). However, to our understanding, the finding of the present study is the first case showing that heterogeneity of the tumour stroma also confer poor prognosis. Underlying mechanisms should be further explored and the concept should be further validated in other tumour types and with other stroma markers. Presently, the stroma heterogeneity can be hypothesised 
to confer an increased capacity of tumours to thrive and grow in different environments. Concerning the findings from ovarian cancer, future studies should also be performed to specifically investigate if the survival association detected in this study is reflecting effects on intrinsic aggressiveness or response to chemotherapy.

In conclusion, this study identifies expression levels and variability of perivascular PDGFR- $\beta$ status as an independent prognostic marker in a population-based cohort of RCC. Findings suggest validation concerning biomarker potential in additional cohorts and should also prompt to continued experimental studies for identification of biological mechanism(s) underlying the associations between perivascular PDGFR- $\beta$ and survival.

\section{ACKNOWLEDGEMENTS}

Members of the AÖ group are acknowledged for support and constructive criticism throughout the study. The AÖ group is supported from grants from the Swedish Research Council (STARGET network), the Breast Cancer Theme Center (BRECT) at Karolinska Institutet, Swedish Cancer Society, the research funds at Radiumhemmet and Stockholm County Council (ALF).

\section{CONFLICT OF INTEREST}

The authors declare no conflict of interest.

\section{REFERENCES}

Armulik A, Genove G, Betsholtz C (2011) Pericytes: developmental, physiological, and pathological perspectives, problems, and promises. Dev Cell 21: 193-215.

Bertotti A, Papp E, Jones S, Adleff V, Anagnostou V, Lupo B, Sausen M, Phallen J, Hruban cA, Tokheim C, Niknafs N, Nesselbush M, Lytle K, Sassi F, Cottino F, Migliardi G, Zanella ER, Ribero D, Russolillo N, Mellano A, Muratore A, Paraluppi G, Salizzoni M, Marsoni S, Kragh M, Lantto J, Cassingena A, Li QK, Karchin R, Scharpf R, Sartore-Bianchi A, Siena S, Diaz Jr LA, Trusolino L, Velculescu VE (2015) The genomic landscape of response to EGFR blockade in colorectal cancer. Nature 526: 263-267.

Cao Y, Zhang ZL, Zhou M, Elson P, Rini B, Aydin H, Feenstra K, Tan MH, Berghuis B, Tabbey R, Resau JH, Zhou FJ, Teh BT, Qian CN (2013) Pericyte coverage of differentiated vessels inside tumor vasculature is an independent unfavorable prognostic factor for patients with clear cell renal cell carcinoma. Cancer 119: 313-324.

Cheng SH, Liu JM, Liu QY, Luo DY, Liao BH, LI H, Wang KJ (2014) Prognostic role of microvessel density in patients with renal cell carcinoma: a meta-analysis. Int J Clin Exp Pathol 7: 5855-5863.

Cooke VG, Lebleu VS, Keskin D, Khan Z, O'Connell JT, Teng Y, Duncan MB, Xie L, Maeda G, Vong S, Sugimoto H, Rocha RM, Damascena A, Brentani RR, Kalluri R (2012) Pericyte depletion results in hypoxiaassociated epithelial-to-mesenchymal transition and metastasis mediated by met signaling pathway. Cancer Cell 21: 66-81.

Corvigno S, Wisman GB, Mezheyeuski A, Van Der Zee AG, Nijman HW, Avall-Lundqvist E, Ostman A, Dahlstrand H (2016) Markers of fibroblast-rich tumor stroma and perivascular cells in serous ovarian cancer: inter- and intra-patient heterogeneity and impact on survival. Oncotarget 7: 18573-18584.

Furuhashi M, Sjoblom T, Abramsson A, Ellingsen J, Micke P, Li H, BergstenFolestad E, Eriksson U, Heuchel R, Betsholtz C, Heldin CH, Ostman A (2004) Platelet-derived growth factor production by B16 melanoma cells leads to increased pericyte abundance in tumors and an associated increase in tumor growth rate. Cancer Res 64: 2725-2733.

Hong J, Tobin NP, Rundqvist H, Li T, Lavergne M, Garcia-Ibanez Y, QIN H, Paulsson J, Zeitelhofer M, Adzemovic MZ, Nilsson I, Roswall P, Hartman J, Johnson RS, Ostman A, Bergh J, Poljakovic M, Genove G (2015) Role of tumor pericytes in the recruitment of myeloid-derived suppressor cells. J Natl Cancer Inst 107.

Keskin D, Kim J, Cooke VG, Wu CC, Sugimoto H, Gu C, De Palma M, Kalluri R, Lebleu VS (2015) Targeting vascular pericytes in hypoxic tumors increases lung metastasis via angiopoietin-2. Cell Rep 10: 1066-1081.

Landau DA, Carter SL, Stojanov P, Mckenna A, Stevenson K, Lawrence MS, Sougnez C, Stewart C, Sivachenko A, Wang L, Wan Y, Zhang W, Shukla SA, Vartanov A, Fernandes SM, Saksena G, Cibulskis K, Tesar B, Gabriel S, Hacohen N, Meyerson M, Lander ES, Neuberg D, Brown JR, Getz G, Wu CJ (2013) Evolution and impact of subclonal mutations in chronic lymphocytic leukemia. Cell 152: 714-726.

McCarty MF, Somcio RJ, Stoeltzing O, Wey J, Fan F, Liu W, Bucana C, Ellis LM (2007) Overexpression of PDGF-BB decreases colorectal and pancreatic cancer growth by increasing tumor pericyte content. J Clin Invest 117: 2114-2122.

Mezheyeuski A, Lindh MB, Guren TK, Dragomir A, Pfeiffer P, Kure EH, Ikdahl T, Skovlund E, Corvigno S, Strell C, Pietras K, Ponten F, Mulder J, Qvortrup C, Portyanko A, Tveit KM, Glimelius B, Sorbye H, Ostman A (2016) Survival-associated heterogeneity of marker-defined perivascular cells in colorectal cancer. Oncotarget 7: 41948-41958.

Shen C, Kaelin Jr. WG (2013) The VHL/HIF axis in clear cell renal carcinoma. Semin Cancer Biol 23: 18-25.

Song SH, Jeong IG, You D, Hong JH, Hong B, Song C, Jung WY, Cho YM, Ahn H, Kim C-S (2014) VEGF/VEGFR2 and PDGF-B/PDGFR- $\beta$ expression in non-metastatic renal cell carcinoma: a retrospective study in 1091 consecutive patients. Int J Clin Exp Pathol 7: 7681-7689.

Wragg JW, Finnity JP, Anderson JA, Ferguson HJ, Porfiri E, Bhatt RI, Murray PG, Heath VL, Bicknell R (2016) MCAM and LAMA4 are highly enriched in tumor blood vessels of renal cell carcinoma and predict patient outcome. Cancer Res 76: 2314-2326.

Xian X, Hakansson J, Stahlberg A, Lindblom P, Betsholtz C, Gerhardt H, Semb H (2006) Pericytes limit tumor cell metastasis. J Clin Invest 116 642-651.

Yang Y, Andersson P, Hosaka K, Zhang Y, Cao R, Iwamoto H, Yang X, Nakamura M, Wang J, Zhuang R, Morikawa H, Xue Y, Braun H, Beyaert R, Samani N, Nakae S, Hams E, Dissing S, Fallon PG, Langer R, Cao Y (2016) The PDGF-BB-SOX7 axis-modulated IL-33 in pericytes and stromal cells promotes metastasis through tumour-associated macrophages. Nat Commun 7: 11385.

Yao X, Qian CN, Zhang ZF, Tan MH, Kort EJ, Yang XJ, Resau JH, Teh BT (2007) Two distinct types of blood vessels in clear cell renal cell carcinoma have contrasting prognostic implications. Clin Cancer Res 13: 161-169.

This work is published under the standard license to publish agreement. After 12 months the work will become freely available and the license terms will switch to a Creative Commons AttributionNonCommercial-Share Alike 4.0 Unported License.

Supplementary Information accompanies this paper on British Journal of Cancer website (http://www.nature.com/bjc) 